\title{
Protein thiols in spermatozoa and epididymal fluid of rats
}

\author{
J. Seligman ${ }^{1}$ and R. Shalgi ${ }^{2}$ \\ ${ }^{1}$ Department of Human Genetics, and ${ }^{2}$ Department of Embryology and Teratology, Sackler School \\ of Medicine, Tel Aviv University, Ramat Aviv, Tel Aviv 69978, Israel
}

\begin{abstract}
Summary. Thiol (SH) oxidation to disulphides (SS) is thought to be involved in sperm chromatin condensation and tail structure stabilization, which occur during maturation of spermatozoa. Previously developed procedures, using the fluorescent labelling agent monobromobimane $(\mathrm{mBBr})$, enabled us to study the thiol-disulphide status of spermatozoa. Electrophoretic separation of labelled sperm proteins from the caput and cauda regions showed that during maturation thiol oxidation occurs in many protein fractions from the tail and that the magnitude of oxidation differs between proteins. Among the protein bands, one major band (MPB), probably a dense fibre constituent, is quantitatively prominent. $\mathrm{N}$-Ethylmaleimide (NEM) or $\mathrm{mBBr}$ alkylation (of intact spermatozoa) changes the mobility of the caput MPB, but not that of the cauda MPB. The results indicated that the altered mobility of MPB is mainly due to a change in its shape, possibly resulting from the alkylation of a few critical SH groups. Epididymal fluid proteins contain both SH and SS. The thiol and disulphide content of the various epididymal proteins appears similar, although some diminution in fluorescence is seen in epididymal fluid proteins from the cauda region as compared with those from the caput region. The prominent changes in thiol status occur in the spermatozoa.
\end{abstract}

Keywords: thiols; epididymis; sperm maturation; rat

\section{Introduction}

Motility and fertilizing capacity of spermatozoa develop as they mature during passage through the epididymis (Yanagimachi, 1988). During maturation, most sperm structures, such as the chromatin, midpiece and tail components, gradually become stabilized (Calvin \& Bedford, 1971; Bedford et al., 1973; Bedford \& Calvin, 1974a; Pellicciari et al., 1983). The involvement of disulphide formation in stabilizing sperm structures during sperm maturation, mainly in the sperm chromatin, has been studied by several biochemical methods (Marushige \& Marushige, 1975; Mercado et al., 1976; Saowaros \& Panyim, 1979; Miller \& Masui, 1982; Pellicciari et al., 1983), but there has been little information on the thiol status of proteins from the tail.

Attempts to follow thiols in sperm protein fractions have been based on the use of $\left[{ }^{14}\right.$ C $]$ iodoacetamide (Calvin et al., 1975; Sattayasai \& Panyim, 1982). We have developed procedures for the determination of sperm thiols (SH) and disulphides (SS) (Shalgi et al., 1989) based on the use of the fluorescent thiol labelling agent monobromobimane (mBBr) (Kosower \& Kosower, 1987). Labelling by $\mathrm{mBBr}$ can be carried out in the intact spermatozoa prior to fractionation, thus avoiding possible thiol modification and loss during subsequent cell fractionation and analysis. These procedures allow (i) the morphological evaluation and quantitative determination of SH and SS in whole spermatozoa and subcellular fractions and (ii) the analysis of changes in thiol status by electrophoretic separation of labelled sperm proteins. During maturation in rat epididymis, oxidation of sperm thiols occurs both in sperm heads and in tails between the caput and 
cauda regions (Shalgi et al., 1989). In this study, the dynamics of sperm protein thiols during maturation was further investigated and the thiol disulphide status in epididymal tissue and fluid surrounding the spermatozoa was studied.

\section{Materials and Methods}

Materials and media. Dithiothreitol (DTT), sodium dodecyl sulphate (SDS), $N$-ethylmaleimide (NEM), ethylenediamine-tetraacetic acid (EDTA) and phenyl methyl sulphonyl fluoride (PMSF) were purchased from Sigma Chemical Co. Monobromobimane ( $\mathrm{mBBr}$, Calbiochem-Behring) was dissolved in acetonitrile and kept as a $50 \mathrm{~mm}$ stock solution in the dark (Kosower et al., 1979). Buffers used were: (a) phosphate-buffered saline (PBS) containing $135 \mathrm{~mm}-\mathrm{NaCl}$ and $10 \mathrm{~mm}$ sodium phosphate buffer $\mathrm{pH}=7 \cdot 4$; (b) Krebs-Ringer-phosphate (Ringer), was prepared as described by Brooks \& Higgins (1980) with a final composition of $150 \mathrm{~mm} \mathrm{Na}^{+}, 4 \cdot 8 \mathrm{mM} \mathrm{Ca}{ }^{2+}, 1 \cdot 2 \mathrm{mM} \mathrm{Mg} \mathrm{Mg}^{2+}, 129 \mathrm{~mm}$ $\mathrm{Cl}^{-}, 15 \cdot 5 \mathrm{mM} \mathrm{PO}_{4}{ }^{3-}, 1.2 \mathrm{mM} \mathrm{SO}_{4}{ }^{2-}$ and $10 \mathrm{~mm}$ glucose, and (c) $10 \mathrm{~mm}$ Tris- $\mathrm{HCl}, \mathrm{pH}=7.6$.

Isolation of epididymal luminal fuid and spermatozoa. Spermatozoa and epididymal luminal fluid were obtained from sexually mature Wistar-derived male rats. The isolation of epididymal luminal fluid and spermatozoa was carried out as described by Brooks \& Higgins (1980). Epididymal tissue was cleared of blood and the caput, corpus and cauda regions were obtained by cutting the tube. Pieces of tissue were shaken in Ringer at $37^{\circ} \mathrm{C}$ for $15 \mathrm{~min}$ to allow the release of the spermatozoa and the fluid originally contained within the lumen of the epididymal tubule. The tissue was collected with a Pasteur pipette and discarded and the suspension was centrifuged at $600 \mathrm{~g}$ for $10 \mathrm{~min}$ to sediment the spermatozoa. The supernatant containing the luminal fluid was retained. The spermatozoa were washed twice more by resuspension and centrifugation in fresh Ringer.

Labelling of thiol groups with monobromobimane. Sperm thiol groups were labelled with $\mathrm{mBBr}$ as described by Shalgi et al. (1989). Briefly, aliquots of washed spermatozoa were incubated with or without $1 \mathrm{~mm}$ DTT at $37^{\circ} \mathrm{C}$ for $10 \mathrm{~min}$. Samples were then washed twice by centrifugation for $10 \mathrm{~min}$ at $600 \mathrm{~g}$, resuspended in PBS to $4-8 \times 10^{6}$ spermatozoa/ml and labelled with $\mathrm{mBBr}$. To block reactive thiols, samples were treated with $10 \mathrm{mM} N E M$ at $37^{\circ} \mathrm{C}$ for $30 \mathrm{~min}$, washed and then labelled with $\mathrm{mBBr}$. In some experiments, spermatozoa were first solubilized in $5 \%$ SDS and $1 \mathrm{~mm}$ DTT and the labelling of the solubilized spermatozoa carried out at a final $\mathrm{mBBr}$ concentration of $2.5 \mathrm{~mm}$ for $20 \mathrm{~min}$.

Electrophoretic analysis of sperm proteins. After labelling of intact spermatozoa, the cells were solubilized by incubation in $5 \%$ SDS and $1 \mathrm{~mm}$ DTT in $37^{\circ} \mathrm{C}$ for $30 \mathrm{~min}$ in the presence of $1 \mathrm{~mm}$ EDTA and $0.5 \mathrm{~mm}$ PMSF. For electrophoretic analysis, 3\% 2-mercaptoethanol (ME) was added to the solubilized spermatozoa, followed by sonication for 10 s to liquefy the DNA. The samples were loaded on SDS-polyacrylamide gel electrophoresis (SDSPAGE) as described by Laemmli (1970). After the electrophoretic separation, the gels were observed and photographed under ultraviolet illumination to detect the fluorescent protein bands (Kosower \& Kosower, 1987). The gels were then stained with Coomassie Brilliant Blue and photographed again. Densitometric profiles of the fluorescent and the stained gels were obtained by using the films of the gels.

Labelling and analysis of epididymal luminal fluid. The luminal fluid was diluted with Ringer buffer and incubated for $10 \mathrm{~min}$ without or with ImM DTT at $37^{\circ} \mathrm{C}$ for $10 \mathrm{~min}$. Labelling was then carried out in the dark for $20 \mathrm{~min}$ at a final $\mathrm{mBBr}$ concentration of $2.5 \mathrm{mmol} / 1$ in the presence or absence of DTT. The labelled solution was centrifuged at $50000 \mathrm{~g}$ for $90 \mathrm{~min}$ at $4^{\circ} \mathrm{C}$ and the supernatant was dialysed for $24 \mathrm{~h}$ at $4^{\circ} \mathrm{C}$ against distilled water, freeze-dried and redissolved in $10 \mathrm{~mm}$ Tris- $\mathrm{HCl}, \mathrm{pH} \mathrm{7.6}$. The samples were then electrophoresed on SDS-PAGE and the gels were analysed as described for sperm proteins.

Histochemical detection of thiols and disulphides in the epididymal tissue. Epididymal tissues were fixed in a solution of paraformaldehyde and picric acid. Serial sections of $6 \mu \mathrm{m}$ were prepared and mounted on slides. One set was stained with haematoxylin and eosin and the others were retained for histochemical labelling. The procedure for labelling with $\mathrm{mBBr}$ was carried out according to the methods of Gainer \& Kosower (1980) with slight modifications. The sections were washed in xylene for $40 \mathrm{~min}$ to remove the embedding material, followed by washes in 100, 96,70 and $50 \%$ ethanol for $15 \mathrm{~min}$ each and then washed with PBS + ImM EDTA. The sections were incubated with or without $10 \mathrm{~mm}$ DTT in PBS + EDTA at $37^{\circ} \mathrm{C}$ for $10 \mathrm{~min}$, washed twice with PBS + EDTA and labelled with mBBr. Labelling was carried out in the dark for $10 \mathrm{~min}$, at a final $\mathrm{mBBr}$ concentration of $1.5 \mathrm{mmol} / 1$ and was followed by 2 washes.

\section{Results}

Spermatozoa, isolated from the caput and cauda of the rat epididymis, were solubilized in SDS + DTT, and proteins were analysed by SDS-PAGE electrophoresis. When stained with Coomassie blue, electrophoretic profiles displayed a series of protein bands ranging in molecular mass from $\sim 95 \mathrm{kDa}$ to $16 \mathrm{kDa}$ with one major protein band (MPB) at $\sim 27 \mathrm{kDa}$ (Fig. 1). The protein profiles 


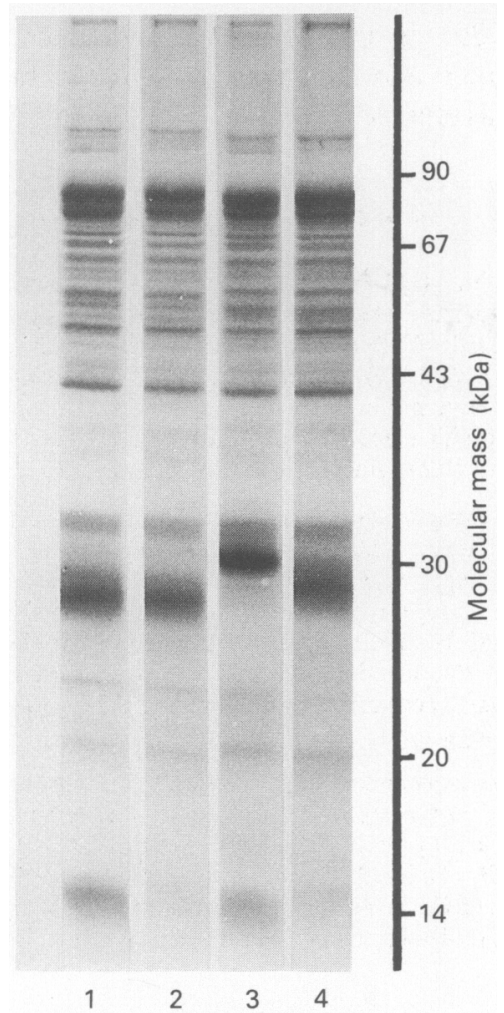

Fig. 1. Polyacrylamide-sodium dodecyl sulphate gel electrophoresis of sperm proteins from caput (lanes 1 and 3 ) and cauda ( 2 and 4 ) epididymides; $N$-ethylmaleimide alkylated (lanes 3 and 4), without alkylation (lanes 1 and 2). Approximate molecular masses are as indicated from migration of known protein standards.

of spermatozoa from the caput and cauda regions appeared similar for most bands, with the exception of a single band at $14 \mathrm{kDa}$ (Fig. 1).

To characterize the differences in protein thiols during maturation, fluorescence and protein staining following electrophoretic separation of sperm proteins from the caput and cauda regions were compared. Caput spermatozoa presented a high number of fluorescent protein bands, including the MPB and some minor proteins of low molecular mass ranging from $\sim 30 \mathrm{kDa}$ to $16 \mathrm{kDa}$ (Fig. 2b). Pretreatment of caput spermatozoa with DTT had only a slight effect on the focusing of one fluorescent band $(23 \mathrm{kDa})$ but did not alter the intensity of the various bands. These results indicate that in the caput spermatozoa, the thiols in most or all of the proteins are present as $\mathrm{SH}$. Less fluorescence was observed in cauda sperm samples in most regions of the gel than in that of caput sperm samples, especially in the region of proteins of low molecular mass. Pretreatment of cauda spermatozoa with DTT prior to labelling with $\mathrm{mBBr}$ resulted in a significant increase in fluorescence of these bands, indicating that most of the thiols in these proteins are oxidized to SS in the cauda. The cauda MPB contained both SH and SS as indicated by the moderate decrease in fluorescence from caput to cauda and by the enhancement in fluorescence following DTT treatment of cauda spermatozoa (Fig. 2b).

Under our experimental conditions ( $1 \mathrm{~mm}$ DTT for $10 \mathrm{~min}$ at $37^{\circ} \mathrm{C}$ ), spermatozoa remained intact and morphology was not altered. In order to expose any possible inaccessible thiols and disulphides, spermatozoa were solubilized in SDS and DTT and the proteins in the solubilized spermatozoa labelled with $\mathrm{mBBr}$. Solubilization of caput spermatozoa, prior to $\mathrm{mBBr}$ labelling, did not significantly alter the extent of fluorescence of the various bands (Fig. 2b, lanes 3, 5). 
(a)

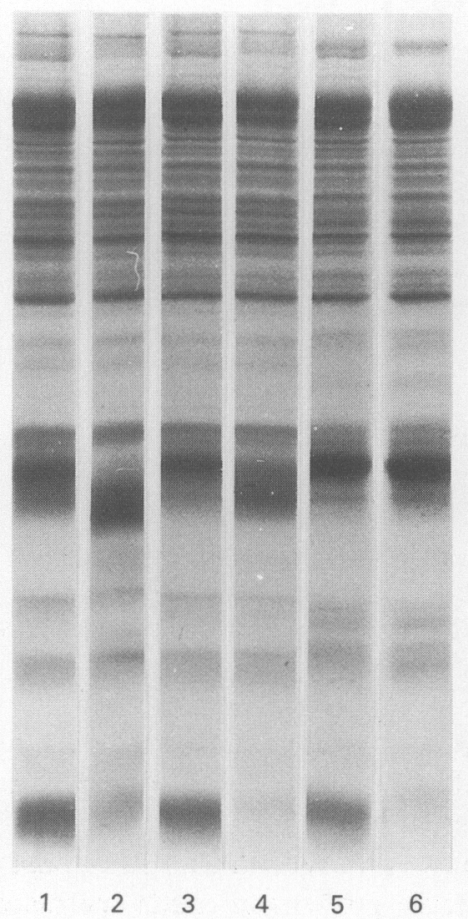

(b)

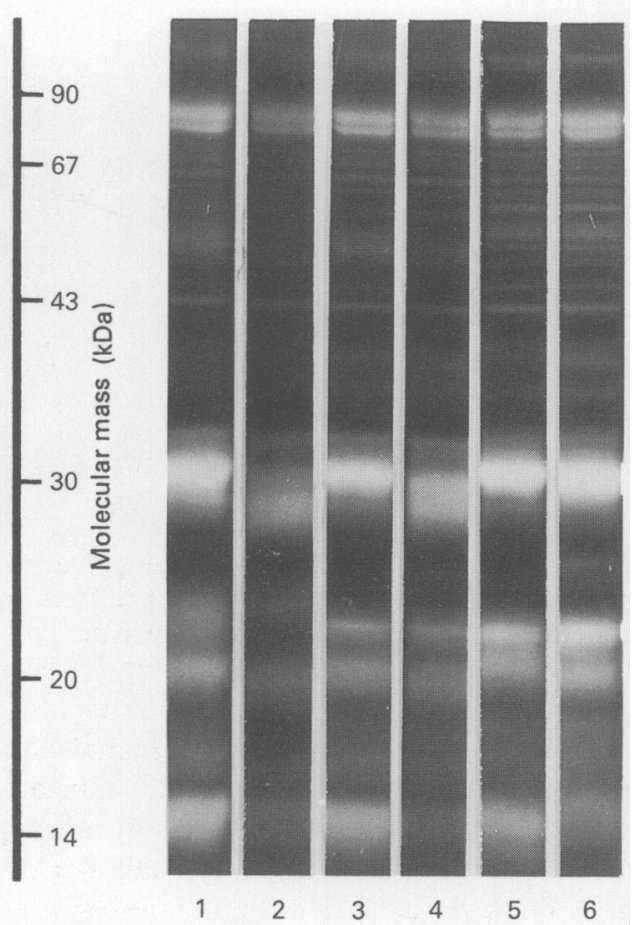

Fig. 2. Polyacrylamide-sodium dodecyl sulphate gel electrophoresis of monobromobimanelabelled sperm proteins from caput (lanes 1,3 and 5) and cauda (2, 4 and 6) epididymides. (a) Coomassie Brilliant Blue stain, (b) fluorescence illumination. Without dithiothreitol (DTT) pretreatment (lanes 1 and 2), after DTT treatment (3 and 4) and after solubilization with $\operatorname{SDS}+\operatorname{DTT}(5,6)$.

(a)

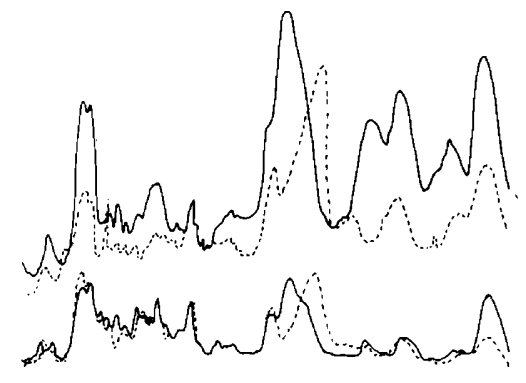

Fig. 3. Densitometry illustration of the polyacrylamide gel electrophoresis profile of sperm proteins labelled with monobromobimane from caput $(-)$ and cauda $(--)$ epididymides; (a) fluorescence, (b) Coomassie Brilliant Blue stain (for origin of the gel on the left, see Fig. 2a lanes 1 and 2, and Fig. 2b lanes 1 and 2).

Solubilization of cauda spermatozoa prior to labelling led to a slight increase in fluorescence of most bands, compared to that of DTT-treated intact spermatozoa (Fig. $2 b$ lanes 4,6 ). It was therefore concluded that most of the disulphides in the intact cauda spermatozoa are reactive to $1 \mathrm{~mm}$ DTT. A small fraction of disulphides in the cauda spermatozoa is not reduced by DTT and becomes exposed upon sperm solubilization. 
(a)

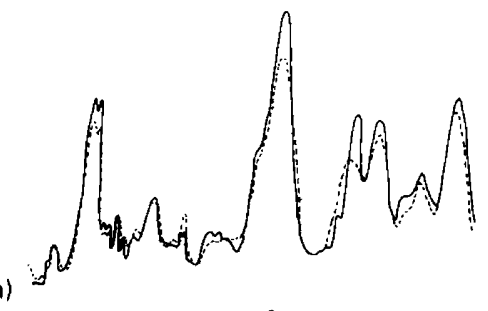

(b)

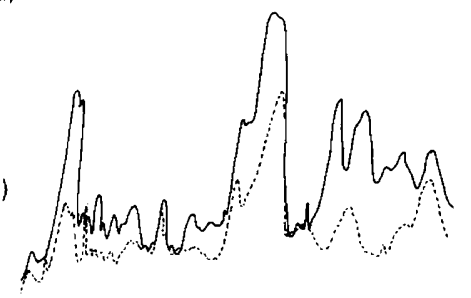

Fig. 4. Densitometry illustration of the polyacrylamide gel electrophoresis profile of sperm proteins labelled with monobromobimane from (a) caput and (b) cauda epididymides. After treatment with dithiothreitol (-); untreated (-- ); (for origin of the gel on the left, see Fig. 2a lanes 1 and 3 for caput and lanes 2 and 4 for cauda epididymides).

The fluorescence of protein bands compared with protein content is illustrated by densitometry bands of proteins labelled with $\mathrm{mBBr}$ and stained with Coomassie blue. In the absence of DTT, there are some highly fluorescent proteins in caput spermatozoa (Fig. 3). One group is that of low molecular weight proteins. These bands stain weakly in Coomassie blue but show high fluorescent labelling. A marked decrease in the fluorescence of these proteins in cauda spermatozoa is not related to protein content which remained unchanged. The amount of MPB also remained unchanged with a moderate decrease in its fluorescence. Densitometry of cauda spermatozoa after DTT treatment showed an increase in labelling in most protein bands. Under these conditions, the fluorescence profiles of caput and cauda proteins appeared similar (Fig. 4), demonstrating that the total amount of thiols and disulphides was not altered during maturation. Densitometric scans of cauda sperm proteins labelled after solubilization revealed that an additional small amount of SS is reduced, as compared with the DTT-treated intact spermatozoa (Fig. 5).

Blocking reactive thiols in spermatozoa with NEM changed the mobility of caput MPB (Fig. 1, lanes 1 and 3). The NEM-alkylated MPB from caput spermatozoa moved slower in the gel and was concentrated in a sharp band. In contrast, the mean mobility of cauda MPB was shifted slightly as the apparent molecular mass of the altered, diffuse species ranged between 27 and $30 \mathrm{kDa}$ (Fig. 1, lanes 2 and 4). Corpus MPB behaved like caput MPB (not shown).

As in NEM alkylation, blocking reactive thiols with $\mathrm{mBBr}$ in spermatozoa changed the mobility of caput MPB with no apparent effect on the mobility of cauda MPB (Fig. 2a, lanes 1-4). Densitometry also clearly revealed the change of MPB mobility after alkylation (Fig. 3). Solubilization of caput spermatozoa prior to labelling did alter migration of MPB; yet, under the same conditions, MPB from cauda spermatozoa changed its mobility and migrated similarly to caput MPB (Fig. 2a, lanes 5 and 6).

Electrophoresis of epididymal fluid samples collected from different regions of the duct gave similar banding patterns (Fig. 6), with 6-8 major bands and over 30 total bands in all regions. The degree of expression of some bands differed. Analysis of fluorescence patterns of epididymal fluid proteins revealed that they contained SS and SH in both the caput and cauda epididymides; the fluorescence being stronger for the caput epididymal fluid proteins.

Histochemical evaluation of thiol status of epithelial cells in caput and cauda epididymides are presented in Fig. 7. Moderate fluorescence was seen in the different elements of the tube in both caput and cauda segments. Following DTT treatment, the fluorescence of all the elements was 


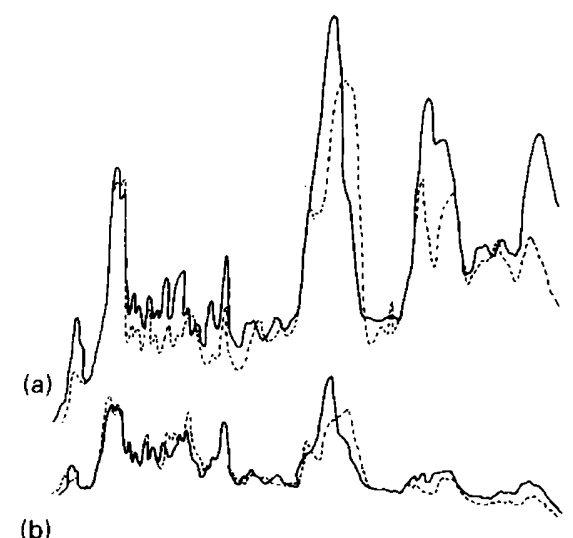

Fig. 5. Densitometry illustration of the polyacrylamide gel electrophoresis profile of sperm proteins labelled with monobromobimane from cauda epididymis; (a) fluorescence, (b) Coomassie Brilliant Blue stain. After DTT treatment with dithiothreitol (-- ); after solubilization (-); (for origin of the gel on the left, see Fig. 2a lanes 4 and 6).

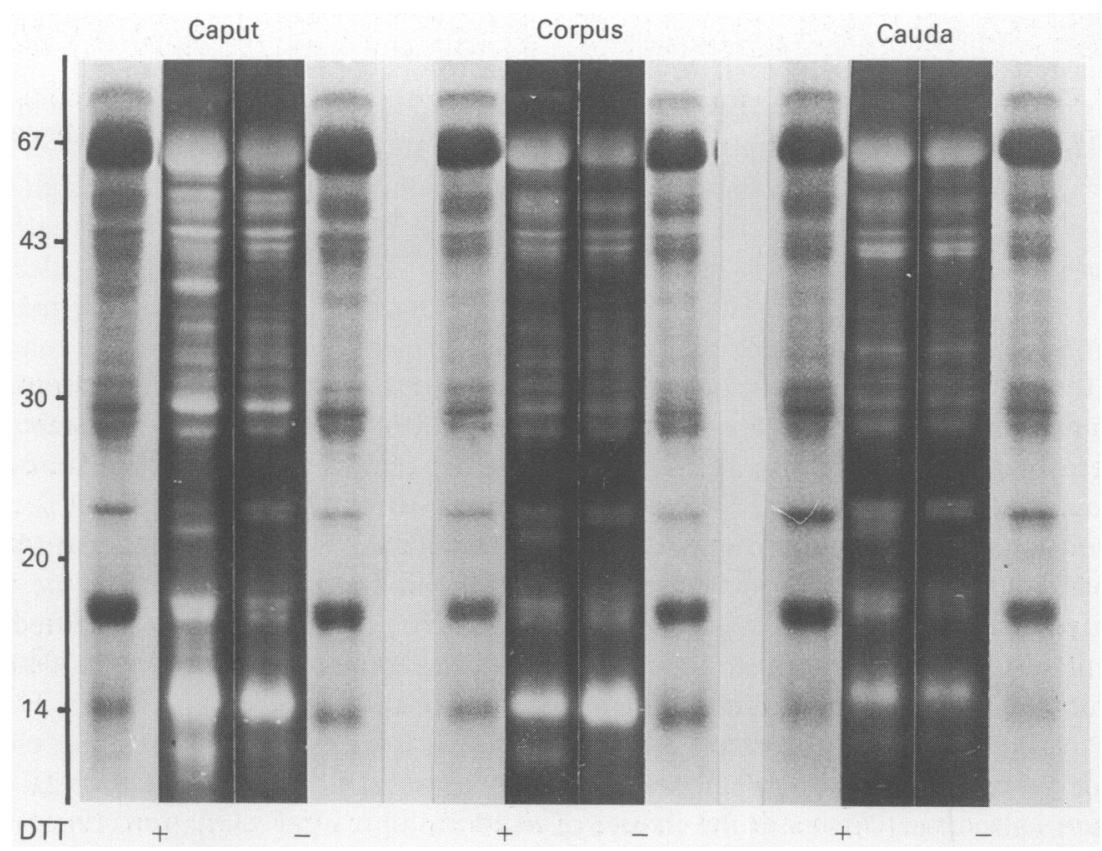

Fig. 6. Polyacrylamide--sodium dodecyl sulphate gel electrophoresis of monobromobimanelabelled epididymal fluid from caput, corpus and cauda epididymides. Fluorescence (middle lanes) and Coomassie Brilliant Blue stain; with (+) and without (-) treatment with dithiothreitol (DTT).

stronger, indicating the presence of SS and SH groups in the epithelial cells and in the connective tissue, with no significant difference between caput and cauda regions. In contrast, the spermatozoa in the lumen showed a difference in the fluorescent intensity between caput and cauda, with significant enhancement of the fluorescence in cauda spermatozoa after DTT treatment (Fig. 7). These results are consistent with those obtained by fluorescent microscopy of the labelled sperm cells isolated from the caput and cauda (Shalgi et al., 1989). 

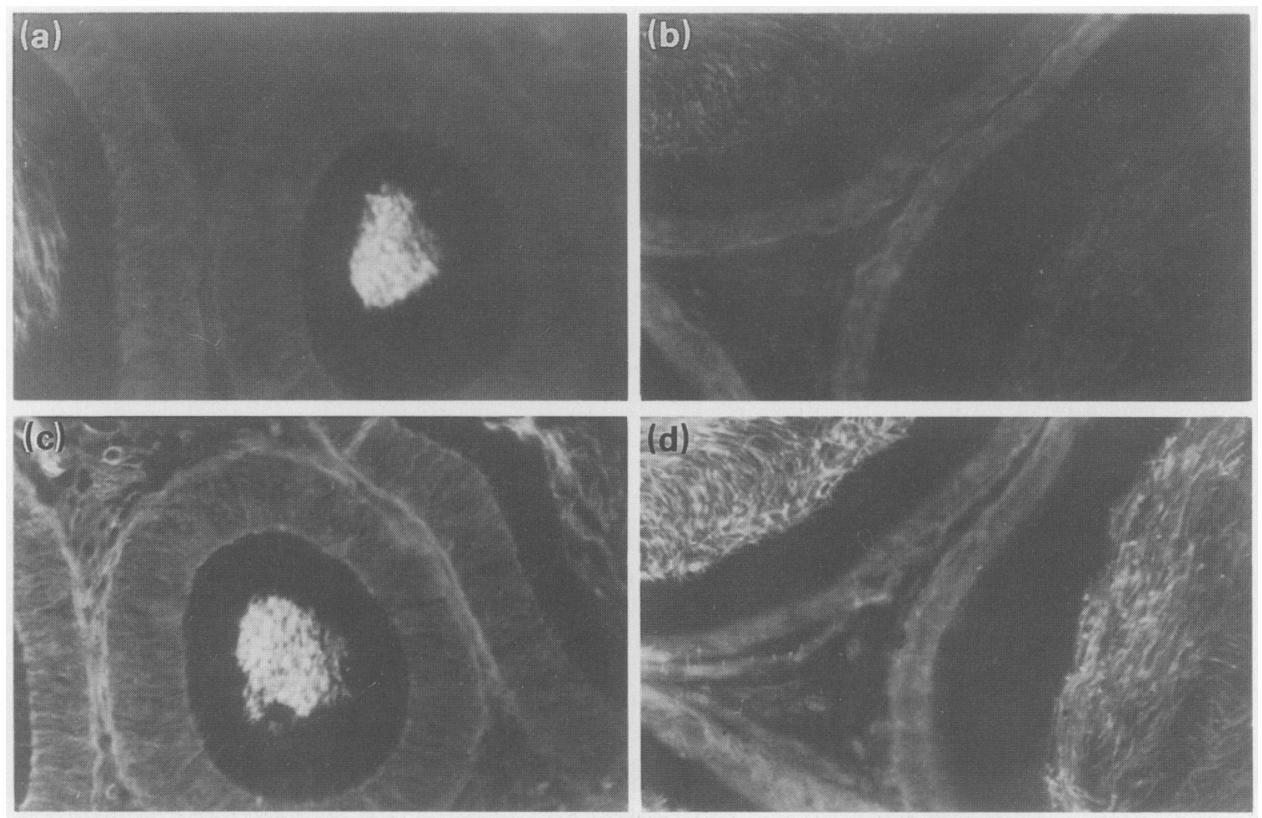

Fig. 7. Cross-section of caput (a and c) and cauda (b and d) epididymal tissue. Epifluorescence; sections labelled with monobromobimane without ( $a$ and $b$ ) and with ( $c$ and d) treatment with dithiothreitol $(\times 250)$.

\section{Discussion}

A shift in the status of protein thiols occurs in rat spermatozoa as they undergo maturation during their passage through the epididymis (Shalgi et al., 1989). We previously found that the total content of thiols and disulphides in spermatozoa did not change during passage from the caput to the cauda region, but that thiols were oxidized to disulphides in the heads and tails of spermatozoa. Electrophoretic analysis of tail proteins from mBBr-labelled cauda spermatozoa showed the presence of disulphides in many fractions (Shalgi et al., 1989). In the present work, we found that, during the passage of spermatozoa from caput to cauda epididymides, thiol oxidation occurred in many tail protein fractions and the magnitude of oxidation differed among proteins. Densitometric scans indicated that the total amount of thiols in caput and cauda proteins is similar. These results are thus consistent with those obtained by quantitative analysis (Shalgi et al., 1989).

The rat sperm tail is very large and contains 4 times as much protein as the head (Shalgi et al., 1989). Most of the protein bands revealed in this study by SDS-PAGE were those of the tail structures, since, under our experimental conditions, the protamine, which is the major head protein, does not migrate. Little is known about highly organized flagella, and the distribution, organization and function of specific sperm tail proteins have not been elucidated (Eddy, 1988).

The dense fibres are very pronounced in the rat sperm tail. Dense fibres from rat spermatozoa have been isolated (Price, 1973; Calvin, 1979; Olson \& Sammons, 1980; Vera et al., 1984; Oko, 1988). Various protein fractions have been described, ranging in molecular mass from 11 to $87 \mathrm{kDa}$, but no consensus has been reached on the number of protein fractions present or their molecular size. Fibrous sheath and perforatorium polypeptides have been described also (Oko, 1988; Oko \& Clermont, 1988), ranging in molecular mass from 11 to $90 \mathrm{kDa}$. In the present work, the sperm protein profiles included proteins in these molecular mass ranges, which include mostly thiols in the caput region and both thiols and disulphide groups in the cauda region. 
Using SDS and DTT, Bedford \& Calvin (1974a) demonstrated the presence of thiols and disulphides in dense fibres, connecting piece, fibrous sheath and outer mitochondrial membrane. Other studies reported high cysteine content in proteins from the outer mitochondrial membrane (Pallini et al., 1979), accessory fibres (Baccetti et al., 1976) and perforatorium (Olson et al., 1976). Several studies have confirmed that the low molecular mass polypeptide bands of the dense fibres have a high cysteine content (Calvin, 1979; Baccetti et al., 1976; Olson \& Sammons, 1980; Vera et al., 1984). A major band/s in the range of 26-32 kDa corresponds probably to the MPB observed in the present study. Using $\left[{ }^{14} \mathrm{C}\right]$ iodoacetamide, Sattayasai \& Panyim (1982) determined SH concentrations in some sperm protein fractions in the range of $13-32 \mathrm{kDa}$. Although the total amount of thiols and disulphides was not evaluated in their work, they showed that these proteins included a major band of $32 \mathrm{kDa}$ which contained high concentrations of thiols in caput, but not in cauda, spermatozoa.

In the present work we found that, in caput spermatozoa MPB contains mostly SH, as shown by the few additional thiols labelled following reduction with DTT in either the intact or solubilized cells. In cauda spermatozoa, some MPB thiols remain reduced while a significant proportion is present as disulphides, as shown by the extent of fluorescence of labelled MPB in the DTT-treated compared with the untreated intact cells. Some additional SS groups are reduced only upon sperm solubilization in DTT-SDS. These results indicate the presence of inter- or intrachain nonreactive 'buried' disulphides in the cauda MPB.

Alkylation with $\mathrm{mBBr}$ of DTT-SDS solubilized spermatozoa changed the mobility of caput and cauda MPB. Under these conditions, both caput and cauda MPB moved in the gel more slowly than cells solubilized in SDS-DTT and not alkylated (compare Fig. 1 lanes 1 and 2 with Fig. 2 lanes 5 and 6). Changes in the mobility of dense fibre proteins occur also after carboxymethylation (Calvin, 1979; Olson \& Sammons, 1980). NEM or mBBr alkylation of intact spermatozoa changed the mobility of caput MPB, but not that of cauda MPB. DTT treatment of intact cauda cells reduced most of the disulphides (Fig. 5), only a small additional fraction of SS being reduced upon solubilization. However, alkylation of this fraction of SH was sufficient to change MPB mobility significantly. A change in protein migration induced by reduction of disulphide bonds has been reported by Knudsen et al. (1985) and Ruoslahti \& Pierschbacher (1987). It has been proposed that internal disulphide bonds are more critical to the conformation of those protein bands (Knudsen $e t$ al., 1985). The change in MPB mobility observed here could be due to a change in the size and/or shape of the molecule upon thiol alkylation. Our results indicate that the altered mobility is mainly due to a change in the shape of the protein and possibly results from the alkylation of a few critical SH groups.

A direct involvement of epididymal secretory proteins as mediators in the process of sperm maturation has been reported. Association of antibodies directed against epididymal proteins inhibits fertilization (Moore \& Hartman, 1986; Cuasnicu et al., 1984). Special attention has been focused on some acidic glycoproteins in the range of $27-37 \mathrm{kDa}$. These glycoproteins have been given several names (Cameo \& Blaquier, 1976; Lea et al., 1978; Brooks \& Higgins, 1980; Jones et al., 1980; Faye et al., 1980; Wong \& Tsang, 1982). In the present study, electrophoretic separation of epididymal fluid showed proteins in these molecular mass ranges which contain both SS and $\mathrm{SH}$. The protein profiles from the various epididymal regions appeared similar with only a few differences between caput and cauda. These results are consistent with those of Hamilton (1981). In the present work we showed that the proteins in the various epididymal regions contain both SS and SH.

Attempts to clarify the involvement of disulphide formation in sperm maturation have focused mainly on sperm structures; there is no information on epididymal fluid thiols. Brooks \& Tiver (1983) reported on some rat epididymal glycoproteins of $26 \mathrm{kDa}$, which bind by disulphide linkages to an integral sperm membrane protein of $\sim 200 \mathrm{kDa}$. These glycoproteins contain free thiol groups (Brooks, 1985) and a high content of cysteine residues (14 out of 93) in the C-terminal half of the molecule (Brooks et al., 1986). One or several of the proteins shown here to contain both 
thiol and disulphide groups may correspond to these polypeptides, but further study is necessary to identify them.

The epididymal epithelial cells and the intercellular connective tissue contain both SH and SS with no significant differences between the caput and cauda regions, as indicated by the fluorescence of $\mathrm{mBBr}$-labelled histological preparations. Although some differences in thiols and disulphides were observed between caput and cauda in epididymal fluid and tissue, the major change in thiol status involved the sperm cells.

The mechanisms responsible for the selective oxidation of sperm protein thiols to disulphides during sperm maturation are unknown. Thiol oxidase activity in the male reproductive tract has been reported (Chang \& Zirkin, 1978) and it was proposed that this enzyme might play a role in the formation and maintenance of sperm disulphide bonds. The enzyme has been characterized with respect to its reaction with thiols of low molecular mass, but whether it can oxidize thiol groups in proteins is not known. However, it is unlikely that the enzyme would penetrate the sperm cell. Small, nonprotein, epididymal thiols, may be able to penetrate the spermatozoa and could play a role in the oxidation of thiols within the sperm cell. The participation of such thiols in these processes remains to be studied.

Previous studies have suggested that thiol oxidation may play a role in the development of sperm motility (Calvin \& Bedford, 1971; Bedford \& Calvin, 1974b; Bedford, 1975). A more recent study (Cornwall et al., 1988) provides direct evidence for the relationship between thiol oxidation and acquisition of motility by epididymal spermatozoa, demonstrating that caput epididymal spermatozoa require oxidation of thiols to become progressively motile.

The maintenance of thiols in the correct degree of oxidation appears to be important for the events preceding fertilization, since either blockage of free thiols (Reyes \& Rosado, 1975), or reduction of disulphides with dithiothreitol inhibits capacitation, acrosome reaction and egg attachment (Miller \& Masui, 1982; Fleming et al., 1982; Yanagimachi et al., 1983). The possible interaction between thiol proteins (SS and $\mathrm{SH}$ ) in epididymal fluid and sperm surface proteins during epididymal transit and maturation requires further study.

This study was supported by a grant from the Chief Scientist, Ministry of Health, Israel. The authors would like to thank Prof. N. S. Kosower for helpful suggestions on the manuscript.

\section{References}

Baccetti, B., Pallini, V. \& Burrini, A.G. (1976) The accessory fibers of sperm tail III high-sulfur and lowsulfur components in mammals and cephalopods. $J$. Ultrastr, Res, 57, 289-308.

Bedford, J.M. (1975) Maturation, transport and fate of spermatozoa in the epididymis. In Handbook of Physiology, Section VII, vol. V, pp. 303-317. Ed. D. W. Hamilton. American Physiology Society, Bethesda.

Bedford, J.M. \& Calvin, H.I. (1974a) Changes in S-S linked structures of the sperm tail during epididymal maturation, with comparative observations in submammalian species. J. exp. Zool. 187, 181-204.

Bedford, J.M. \& Calvin, H.I. (1974b) The occurrence and possible functional significance of S-S crosslinks in sperm heads, with particular reference to Eutherian mammals. J. exp. Zool. 188, 137-156.

Bedford, J.M., Calvin, H.I. \& Cooper, G.W. (1973) The maturation of spermatozoa in the human epididymis. J. Reprod. Fert. Suppl. 18, 199-213.

Brooks, D.E. (1985) Characterization of $22 \mathrm{kDa}$ protein with widespread tissue distribution but which uniquely present in secretions of the testis and epi- didymis and on the surface of spermatozoa. Biochim. biophys. Acta 841, 59-70.

Brooks, D.E. \& Higgins, S.J. (1980) Characterization and androgen-dependence of proteins associated with luminal fluid and spermatozoa in the rat epididymis. J. Reprod. Fert. 59, 363-375.

Brooks, D.E. \& Tiver, K. (1983) Localization of epididymal secretory proteins on rat spermatozoa. $J$. Reprod. Fert. 69, 651-657.

Brooks, D.E., Means, A.R., Wright, E.J., Singh, S.P. \& Tiver, K.K. (1986) Molecular cloning of the cDNA for androgen-dependent sperm-coating glycoproteins secreted by the rat epididymis. Eur. J. Biochem. 161, $13-18$.

Calvin, H.I. (1979) Electrophoretic evidence for the identity of the major zinc-binding polypeptides in the rat sperm tail. Biol. Reprod. 21, 873-882.

Calvin, H.I. \& Bedford, J.M. (1971) Formation of disulphide bonds in the nucleus and accessory structures of mammalian spermatozoa during maturation in the epididymis. J. Reprod. Fert. Suppl. 13, 65-715.

Calvin, H.I., Hwang, F.H.F. \& Wohlrab, H. (1975) Localization of zinc in dense fiber-connecting piece 
fraction of rat sperm tails analogous chemically to hair keratin. Biol. Reprod. 13, 228-239.

Cameo, M.S. \& Blaquier, J.A. (1976) Androgencontrolled specific proteins in rat epididymis. $J$. Endocr. 69, 47-55.

Chang, T.S.K. \& Zirkin, B.R. (1978) Distribution of sulfhydryl oxidase activity in the rat and hamster male reproductive tract. Biol. Reprod. 17, 745-748.

Cornwall, G.A., Vindivich, D., Tillman, S. \& Chang, T.S.K. (1988) The effect of sulfhydryl oxidation on the morphology of immature hamster epididymal spermatozoa induced to acquire motility in vitro. Biol. Reprod. 39, 141-155.

Cuasnicu, P.S., Gonzalez Echeverria, F., Piazza, A.D., Cameo, M.S. \& Blaquier, J.A. (1984) Antibodies against epididymal glycoproteins block fertilizing ability in rat. J. Reprod. Fert. 72, 467-471.

Eddy, E.M. (1988) The spermatozoon. In The Physiology of Reproduction, pp. 27-67. Eds E. Knobil et al. Raven Press Ltd, New York.

Faye, J.C., Duguet, L., Mazzuca, M. \& Bayard, F. (1980) Purification, radioimmunoassay and immunohistochemical localization of a glycoprotein produced by rat epididymis. Biol. Reprod. 23, 423-432.

Fleming, A.D., Kosower, N.S. \& Yanagimachi, R. (1982) Promotion of capacitation of guinea pig spermatozoa by the membrane mobility agent, $\mathrm{A}_{2} \mathrm{C}$, and inhibition by the disulfides-reducing agent, DTT. Gamete Res. 5, 19-33.

Gainer, H. \& Kosower, N.S. (1980) Histochemical demonstration of thiol and disulfides by the fluorescent labeling agent, monobromobimane: an application to the hypothalamoneurohypophysial system. Histochemistry 68, 309-315.

Hamilton, D.W. (1981) Evidence for $\alpha$-lactalbumin-like activity in reproductive tract fluids of the male rat. Biol. Reprod. 25, 385-392.

Jones, R. \& Brown, C.R., Von glos, K.I. \& Parker, M.G. (1980) Hormonal regulation of protein synthesis in rat epididymis; characterization of androgen-dependent and testicular fluid dependent proteins. Biochem. $J$. 188, 667-676.

Knudsen, K.A., Horwitz, A.F. \& Buck, C.A. (1985) A monoclonal antibody identifies a glycoprotein complex involved in cell-substratum adhesion. Exp. Cell Res. 157, 218-226.

Kosower, N.S. \& Kosower, E.M. (1987) Thiol labeling with bromobimanes. Meth. Enzymol. 143, 76-84.

Kosower, N.S., Kosower, E.M., Newton, G.L. \& Ranney, H.M. (1979) Bimane fluorescent labels: labelling of normal human red cells under physiological conditions. Proc. Natl Acad. Sci. USA 76, 3382-3386.

Laemmli, U.K. (1970) Cleavage of structural proteins during the assembly of the head of bacteriophage $\mathrm{T}_{4}$. Nature, Lond. 227, 680-685.

Lea, O.A., Petrusz, P. \& French, F.S. (1978) Purification and localization of acidic epididymal glycoprotein (AEG): a sperm coating protein secreted by the rat epididymis. Int. J. Androl. Suppl. 2, 592-607.

Marushige, Y. \& Marushige, K. (1975) Transformation of sperm histones during formation and maturation of rat spermatozoa. J. biol. Chem. 250, 39-45.

Mercado, E., Carvajal, G., Reyes, A. \& Rosado, A. (1976) Sulphydryl groups in the spermatozoa membrane. A study with a new fluorescent probe for SH groups. Biol. Reprod. 14, 632-640.
Miller, M. \& Masui, Y. (1982) Changes in the stainability and sulfhydryl level in the sperm nucleus during sperm oocyte interaction in mice. Gamete Res. 5, 167-180.

Moore, H.D.M. \& Hartman, T.D. (1986) Localization by monoclonal antibodies of various surface antigens of hamster spermatozoa and the effect of antibody on fertilization in vitro. J. Reprod. Fert. 70, 175-183.

Oko, R. (1988) Comparative analysis of proteins from the fibrous sheath and outer dense fibers of rat spermatozoa. Biol. Reprod. 39, 169-182.

Oko, R. \& Clermont, Y. (1988) Isolation, structure and protein composition of the perforatorium of rat spermatozoa. Biol. Reprod. 39, 673-687.

Olson, G.E., Hamilton, D.W. \& Fawcett, D.W. (1976) Isolation and characterization of the perforatorium of rat spermatozoa. J. Reprod. Fert. 47, 293-297.

Olson, G.E. \& Sammons, D.W. (1980) Structural chemistry of outer dense fibers of rat sperm. Biol. Reprod. 22, 319-332.

Pallini, V., Baccetti, B. \& Burrini, A.G. (1979) A peculiar cysteine-rich polypeptide related to some unusual properties of mammalian sperm mitochondria. In The Spermatozoon, pp. 141-150. Eds D. W. Fawcett \& J. M. Bedford. Urban and Schwarzenberg Inc., Baltimore-Munich.

Pellicciari, C., Hosokawa, Y., Fukuda, M. \& Manfredi Romanini, M.G. (1983) Cytofluorometric study of nuclear sulphydryl and disulphide groups during sperm maturation in the mouse. J. Reprod. Fert. 68, 371-376.

Price, J.M. (1973) Biochemical and morphological studies of outer dense fibers of rat spermatozoa. J. Cell Biol. 59, 272a.

Reyes, A. \& Rosado, A. (1975) Interference with sperm binding to zona pellucida by blockage of SH groups. Fert. Steril. 26, 201-202.

Ruoslahti, E. \& Pierschbacher, M.D. (1987) New perspectives in cell adhesion: RGD and integrins. Science N. Y. 238, 491-497.

Saowaros, W. \& Panyim, S. (1979) The formation of disulfide bonds in human protamines during sperm maturation. Experientia 35, 191-192.

Sattayasai, N. \& Panyim, S. (1982) Nature of proteins which form disulfide bonds during maturation of rat spermatozoa. Int. J. Androl. 5, 337-344.

Shalgi, R., Seligman, J. \& Kosower, N.S. (1989) Dynamics of the thiol status of rat spermatozoa during maturation: Analysis with the fluorescent labeling agent monobromobimane. Biol. Reprod. 40, 1037-1045.

Vera, J.C., Brito, M., Zuvic, T. \& Burzio, L.O. (1984) Polypeptide composition of rat sperm outer dense fibers. J. biol. Chem. 259, 5970-5977.

Wong, P.Y.D. \& Tsang, A.Y.F. (1982) Studies on the binding of a $32 \mathrm{~K}$ rat epididymal protein to rat epididymal spermatozoa. Biol. Reprod. 27, 1239-1246.

Yanagimachi, R., Huang, T.T.F., Fleming, A.D., Kosower, N.S. \& Nicolson, G.L. (1983) Dithiothreitol, a disulfide-reducing agent, inhibits capacitation, acrosome reaction, and interaction with eggs by guinea pig spermatozoa. Gamete Res. 7, 145-154.

Yanagimachi, R. (1988) Mammalian fertilization. In The Physiology of Reproduction, pp. 135-185. Eds E. Knobil et al. Raven Press Ltd, New York.

Received 4 October 1990 